\title{
System Dynamics Outlook on BIM and LEAN Interaction in Construction Quantity Surveying
}

\author{
Zhaoxi Zhan $^{1} \cdot$ Yutong Tang ${ }^{1} \cdot$ Chen Wang ${ }^{2}$ - Jeffrey Boon Hui Yap ${ }^{3} \cdot$ Yong Seng Lim ${ }^{2}$
}

Received: 17 September 2021 / Accepted: 12 January 2022 / Published online: 30 January 2022

(c) Shiraz University 2022

\begin{abstract}
Lean construction and Building Information Modeling (BIM) are increasingly utilized in quantity surveying (QS) production, yet the dilemma of BIM and LEAN interaction is largely ignored. The main problems occurred in traditional quantity surveying services among public and private organizations are experiencing collisions, uncertainties, ambiguities and complexities, which are expected to be mitigated through the implementation of BIM-LEAN practice. However, due to the absence of enough knowledge and confidence to encounter BIM-LEAN for QS practices, quantity surveyors are hesitant to prosecute this new technology but default back to conventional inefficient working methods. Through a questionnaire survey, this paper is to identify the challenges and strategies in implementing BIM-LEAN in QS practices as well as to develop a conceptual system dynamics model to assist this effort. The challenges related to financial issues such as hardware and software cost and training cost could have more impact on small-and-medium-sized QS firms. Lack of BIM-LEAN experts in organizations could be another barrier to implementing BIM-LEAN in QS practice, and this, in turn, could further affect the decision-making process to adopt BIM-LEAN thus initiating a death spiral.
\end{abstract}

Keywords BIM-LEAN · Quantity surveyors $(\mathrm{QSs}) \cdot$ Next-gen QS production · BIM-LEAN interaction

Chen Wang

wch@hqu.edu.cn

Zhaoxi Zhan

zhaoxi@hqu.edu.cn

Yutong Tang

20013086035@stu.hqu.edu.cn

Jeffrey Boon Hui Yap

bhyap@utar.edu.my

Yong Seng Lim

18013086043@stu.hqu.edu.cn

1 College of Civil Engineering, Huaqiao University, Xiamen 361021, China

2 Intelligence and Automation in Construction Fujian Province Higher-Educational Engineering Research Centre, College of Civil Engineering, Huaqiao University, Xiamen 361021, China

3 Department of Surveying, Lee Kong Chian Faculty of Engineering and Science, Universiti Tunku Abdul Rahman (UTAR), 43000 Kajang, Selangor, Malaysia

\section{Introduction}

Quantity Surveying (QS) service is one of the most important and traditional services in the construction sector (Olsen and Taylor 2017). A quantity surveyor is a professional person who used proper management procedures and technical tools to manipulate and regulate the construction project costs ensuring that the resources of the construction industry are utilized to the best advantage of society by providing, inter alia, the financial management for projects and a cost consultancy service to the client and designer during the whole construction process, yet in recent years, the quantity surveying productions have incurred significant changes in the construction sector (Liu et al. 2016; Fadeyi 2017). Greenstret et al. (2003) considered quantity surveyors as "architectural economists," playing a very important role in the field of construction sector. In complex construction projects, project costs are influenced by the needs of stakeholders and quantity surveyors are required to take responsibility and optimize the cost of the project (Wao and Flood 2016). In this process, it is necessary to generate detailed cost estimates, but it is a very time-consuming task in engineering projects. With the emergence of the conceptual method of 
lean construction and the widespread application of BIM, the construction industry is undergoing tremendous changes in the two important areas of management and technology (Sacks et al. 2010). To gain global competitiveness, quantity measurement also conforms to the development of the industry, integrating lean thinking and information technology with professional knowledge as its additional competitive advantage (Wao and Flood 2016). Although they are conceptually independent, there is a synergistic effect between them. Exploring this synergistic effect can effectively improve the level of project cost estimation (Sacks et al. 2010).

BIM takes an important role in the project management process, providing multiple functions for each party involved. It could execute measurement automation and facilitate the preparation of accurate estimates thus the manual measurement of bills of quantities by hand-writing and scale-ruler would seem no longer be necessary (Alshamrani 2017). However, plenty of information needs to be determined to generate quantities such as classifications, specifications, standardized method of measurement (SMM2), and cost estimate for each design element; thus, the critical roles of QS based on BIM are changing and becoming different from previous roles (Swei et al. 2017). Modern QSs can use BIM effectively to achieve meaningful whole-life value methods for measuring and evaluating building sustainability (Nagalingam et al. 2015). The research showed that using BIM software can realize automation and improve the efficiency of project cost estimation (Alufohai 2013). To remain relevant and competitive, QS professionals are now more than ever scanning their business landscape to distinguish and to adjust to the significant changes to their QS production (Fadeyi 2017). The QS production has evolved from a paper-based system to an IT-based system and now a digital-based system triggered by BIM (Liu et al. 2016).

To rationally arrange the position of information technology in QS services, introducing lean thinking will add value while eliminating waste without sacrificing quality or productivity. Lean construction incorporates the characteristics of engineering project management on the basis of absorbing the advanced management concepts of the manufacturing industry. Its core idea is to achieve the goal of project construction under the conditions of ensuring quality, shortest construction period, and least resource consumption. Lean construction promotes the transformation of construction management from extensive to refined, and through information sharing, the joint participation, coordination, and decision making of personnel have been realized. Stakeholders in the Nigerian construction industry believed that the use of lean construction had great benefits in shortening the construction period and saving project costs (Babalola et al. 2019). With its information and visualization functions (Ding et al. 2012), BIM provides excellent services for project lean construction. It associates the building model with information such as project progress, resources, and costs. The main problems occurred in traditional QS services among public and private organizations are experiencing collisions, uncertainties, ambiguities, and complexities (Abanda et al. 2017). Traditional QS was affected by poor information in design, inaccurate transfer of building information and wrong deliveries due to the involvement of multiple disciplines such as architects and engineers (structural, mechanical, and electrical) (Liu et al. 2016). The problems of frequent design changes, inadequate drawings, and specifications caused lack of information, late distribution of drawings, and interrelated matter of conformity between consultants are the root causes of fragmentation, overrun for time and cost, conflict, as well as low quality and productivity of works (Matthews et al. 2018; Yap and Skitmore 2018). The interaction between BIM and lean connects the project design with the construction phase, maintenance phase, and operation phase (Dave et al. 2015; Almarshad 2012; Al Hattab and Hamzeh 2015; Oskouie et al. 2012), so that such needs can be met. Nowadays, researchers are increasingly interested in the interactive applications of BIM and Lean. Their interaction provides visual processes, shared information and convenient communication, which seems very promising (Saieg et al. 2018). Their combined application has a greater improvement impact on the project than the single application. However, most of the previous research focused on the theory of BIM and LEAN, and there was little practice in the development of BIM-LEAN tools (Sepasgozar 2021).

Notwithstanding, the plethora of research on the application of BIM-LEAN interaction in construction management in the recent past, the full potential of BIM-LEAN for quantity surveying practice is not effectually exploited. QSs are lagging in BIM and LEAN applications compared to architects and engineers (Swei et al. 2017). The QS production has been slow to evolve to fully leverage the potential of BIM in advancing project management (Aibinu and Venkatesh 2014). Most professionals and QS companies are in the exploration and experimentation stage for the interaction of BIM and lean construction. If rooted in the correct understanding of production theory concepts, the synergy effects can be explored to improve the QS process (Sacks et al. 2010). Though BIM is capable of providing precise cost information by combining graphical and non-graphical data models, due to the absence of enough knowledge and confidence on the ability of BIM for QS practices, quantity surveyors are hesitant to prosecute this new interaction but default back to conventional inefficient working methods. However, BIM will not bring additional difficulties to the traditional QS process. Compliance with standard measurement methods and limited market demand will not significantly hinder the deployment of BIM. Once the final design 
model is involved, quantity surveyors can use BIM to support their professional services (Babatunde et al. 2019). Near-term studies by Wang et al. (2018) and Liu et al. (2016) concerning innovation development in the Malaysian and Chinese construction sector sturdily support the notion that technical innovation significantly enhances the performance of small-and-medium enterprises (SMEs) such as construction cost management services. Therefore, the interaction on BIM-LEAN plays a positive role in modern QS, and it is necessary to explore the application of BIM-LEAN in QS.

This study aims to explore the challenges and strategies of implementing BIM-LEAN interaction in modern QS. A conceptual system dynamics model was proposed to assist in this important work. The main problems existing in traditional QS are conflict, uncertainty, ambiguity, and complexity, and the implementation of BIM-LEAN plays a positive role in solving these problems. This study had an in-depth understanding of the barriers of BIM-LEAN interaction between QS. The challenges and strategies on implementing BIM-LEAN in modern QS were obtained through a questionnaire survey. Partial Least Square Structural Equation Model (PLS-SEM) on interaction factors between BIM-LEAN and QS was constructed and data analysis was conducted. The objective was to obtain key challenges and excellent strategies for BIM-LEAN in modern QS. Given the interrelatedness of the variables relating to challenges and strategies to BIM-LEAN interaction for QS services, the conceptualized system dynamics (SD) model in this research mapped the multiple interrelated variables into an integrated graphical representation to enable practical holism among researchers and practicing QS in the construction industry. Improved mental models regarding the underlying dynamics of these variables are needed to stimulate widespread use of BIM-LEAN features toward harnessing the full potential of BIM-LEAN, particularly in advancing project cost management and quantity surveying practices.

\section{BIM-LEAN Interaction and QS Production Evolution}

\subsection{BIM and LEAN Interaction}

The concept of Lean is mainly developed and evolved by Toyota from the Japanese industry. Lean construction is an extension of lean production and lean manufacturing in the construction industry, and its development has been going on for more than 20 years. It promotes the transformation of construction management from extensive to refined and injects new management ideas into engineering projects. As an innovative and integrated work platform, BIM has the ability of visualization and information expression, which provides strong support for the lean management of construction projects (Ding et al. 2012; Saieg et al. 2018). Lean construction and Building Information Modeling (BIM) are increasingly utilized in civil engineering projects (Darko et al. 2020). Some articles studied the interaction between lean construction and BIM and implied that a synergy exists between them (Sacks et al. 2013).

Using Structural Building Information Modeling (S-BIM), a flexible environment is provided for collaboration and data exchange with the related fields to Set-based Design (SBD) implementation (Guerra et al. 2020). SBD is a lean design that shares information and cooperates with relevant fields to omit wasting elements and grows productivity in all phases of the project. SBD based on S-BIM enables constructability and economic efficiency analysis to improve efficiency (Lee et al. 2012). The KanBIM concept is "a BIMbased lean production management system for construction." This system provides site-specific interfaces to cope with the construction projects' limitations in managing resources (Oraee et al. 2019). KanBIM is a web-based collaborative interface that relates control to long-term plans and solves the controlling problem based on short-term decisions and vocabulary exchanges between managers and site teams. It is proposed that applying Internet of Things (IoT) standards for real-time task status report from the site can improve lean construction management systems such as KanBIM (Dave et al. 2016). Sacks et al. presented a matrix of 56 interactions between BIM functions and lean building principles juxtaposing them, which supports the idea of BIM and Lean as synergies (2010). Arayici et al. introduced the bottom-up BIM implementation method, learning design workflow and personnel allocation on the basis of learning software programs. This BIM strategy method at the organizational level has improved efficiency in lean architecture practice (Arayici et al. 2011). Koseoglu et al. based on the principles of Lean thinking and improved the project management process by using the mobile BIM process to realize the interaction between BIM and Lean in the process of design, construction, manufacturing, operation, and maintenance (Koseoglu and Nurtan-Gunes 2018). Nascimento et al. (2018) proposed an engineering project management method that combines BIM and lean construction, associating BIM functions and lean principles with PDCA, and greatly reducing rework and waste in industrial construction.

BIM and Lean have a great synergy in controlling interactions and reducing variation (Sepasgozar et al. 2021). Simultaneous usage of these two concepts enables the optimization of the overall time and cost and increment of quality to a remarkable level (Said 2016). Heravi et al. adopted value stream mapping (VSM), just-in-time (JIT), continuous process and total production maintenance (TPM) methods in stages during the entire production and installation process of prefab steel frames, through life cycle assessment and discrete event simulation, respectively, the method evaluates 
the lean technology used. The results show that the energy consumption and $\mathrm{CO} 2$ emissions of the PSF production and installation process have been reduced by $92 \%$ and 4\% (Heravi et al. 2020), and the time and cost have been reduced by $43 \%$ and $17 \%$, respectively (Heravi et al. 2021). This showed that the environmental performance and performance on precast steel frame projects could be significantly improved through lean technology. Modern computer-aided tools for visualization of facilitating processes within the BIM context can manage data effectively to make the state of the process clear to all stakeholders, which is essential for advanced production management techniques implementation such as lean construction concepts (Sacks et al. 2013). BIM adoption enables the construction projects to achieve their goal regarding lean and green outcomes and to solve the challenges of environmental and low productivity issues and gain favorable results (Ahuja et al. 2017). Dallasega et al. (2020) proposed a method to enhance lean construction by combining BIM with virtual and augmented reality, which significantly improved the efficiency of construction project execution. At the same time, academics have widely cited the benefits of consistency between lean thinking and sustainability/green (Fercoq et al. 2016; Garza-Reyes 2015). Ahuja et al. believed that a comprehensive understanding and collaborative application of BIM, lean and green concepts was necessary to solve current problems in the construction industry (Ahuja et al. 2017).

\subsection{Recent Development on BIM and LEAN in QS Services}

Quantity surveying was a profession that dated back to the eighteenth century in the United Kingdom (UK) when quantity surveyors only perform their measurement and valuation works after the projects were constructed (Olsen and Taylor 2017). QSs at that time acted mainly as a tradesman negotiating with the client and architect and performed based on a paper-based system such as blueprints known as 2D drawings (Abanda et al. 2017). In the early nineteenth century, the scopes of quantity surveying work altered to conduct complete price lists before starting the building project, and QSs executed the technique of pre-measuring quantities from design drawings given by architects then converted into "bills of quantities" to get the quotation (Alshamrani 2017). At the end of the twentieth century, the construction sector adopted an ITbased electronic document management system to assist in designing, planning, and operations (Swei et al. 2017). Architects produced drawings more efficiently using computer-aided design (CAD), but the outputs are not much different from the paper-based system in QSs' perspective because QSs still must to take-off quantities manually. The only difference was that QSs could use computer-based excel sheets to list down all quantities (Olsen and Taylor 2017). Nowadays, BIM is applied to the QS for cost estimation and preparation of bills of quantities. The deeper application of BIM in the QS is a hot topic of current research (Ismail et al. 2019).

BIM as a digitization-based system provides a potential solution in automating the QS tasks (Liu et al. 2016). BIM is a successor to the $3 \mathrm{D}$ CAD while the vital functions are added into the 3D BIM model integrating digital models with geometrical and parametric information (Gibson and Hamilton 1994). Babatundeet et al. analyzed the benefits of BIM's powerful data and digital functions to the QS process and found that BIM can help improve efficiency, reliability, accuracy, integration, automation, collaboration, and visual design issues in the design model. By using BIM, the most effective decisions related to sustainable design could be made early in the design and pre-construction stages (Babatunde et al. 2018). Babatunde et al. (2019) identified and evaluated the BIM driving factors related to QS. The main driving factors are: improving the entire life cycle, enhancing decision making and visualization, saving costs and time, supporting the work of quantity surveyors, and reducing the pressure on the government and customers. Therefore, BIM has great potential to inspire all aspects of the quantity measurement industry. It can help QSs reduce arithmetic errors and eliminate many cumbersome tasks in traditional methods, such as bidding and the production of bills of quantities (BQ) (Ying and Kamal 2021; Olatunji et al. 2021). Hence, QSs should fully adopt BIM to improve the costeffectiveness and value of the construction process (Saka and Chan 2020). LEAN could reduce errors with interface and collision checking; reduce timescales and mistake from the interpretation of drawing-based designs; mitigate issues that might increase cost or risk; improve accountability and better life cycle assessment as well as increase certainty of projects by allowing exchange of information among parties, which provides QSs with extra time to execute other valueadded services to enhance the quality of products, instead of taking weekly times to do the time-consuming measurement for taking-off quantities from designs (Grilo and JardimGoncalves 2010). Instead of the traditional duties such as measuring materials and trading works, QS responsibilities also include financial, contractual and commercial management, as well as assisting or leading decision making (Liu et al. 2016). Construction project management and facilities management are potential areas to add value for the future direction of the Quantity Surveying Production. Risks analysis, facilities management, project management, change management, and environmental management also become future roles of quantity surveyors. Ashworth and Hogg (Ashworth et al. 2013) predict in the broader range of QSs' future functions including automated measurement and quantification, sustainability and environmental analysis, facilities 
management, legal services, investment advice, and quality management.

Every implementation of new operational technology consists of risks and challenges and BIM-LEAN interaction in QS services is not an exception especially the resistance in changing current work practices. First and foremost, Dainty et al. (2017) believed that technical issues such as lack of technical expertise, the complexity of the system and lack of support system are the challenges in integrating BIM and LEAN. Besides, poor internet connections and limited access, as well as poor network security, are some examples of technical difficulties (O'Brien 2000). Compatibility and complexity are factors contributing to the acceptance of BIM and LEAN interaction, and it is difficult to ensure data integrity among parties because of interoperability issues such as the capability to exchange data between applications to facilitate automation and avoidance of data re-entry and negative perception of new technology. The obstacles to BIM and LEAN application in the construction industry are generally related to technology, cost, management, personnel and legal aspects. They further underscore that the primary blockades to BIM and LEAN expansion are the scarceness of competent professionals, limited data interoperability and modifications to workflow processes. A consistent observation is also reported by Matthews et al. (2018) on the limited experience and knowledge among practicing construction personnel in Australia.

\section{Research Methods and Procedures}

A total of 500 questionnaire forms were distributed to quantity surveying firms in Malaysia. As part of the questionnaire screening process for data quality inspection, invalid questionnaires returned were eliminated. Firstly, any questionnaire with too many unanswered questions; secondly, any questionnaire with the same or regular answers; thirdly, any questionnaire that does not follow the rules on the question. Following the above screening, 102 questionnaires were considered valid, and the return rate of valid questionnaires was $20.4 \%$. Due to the impact of the COVID-19 pandemic, communication was not timely and resulted in a low number of valid questionnaires. Nonetheless, through strict screening and verification of the quality of the questionnaire, it is ensured that an effective questionnaire has high reference and analytical value. Questions in the survey were structured based on three answering methods, namely: selective method, rating scales method, and open-ended answering method. The questionnaire form was divided into five sections A-D. Section A deals with demographic data including ages, genders, working experience, designation, and registration status in professional bodies, to increase the validity of the survey. Section B concerns the current practices and level of awareness of BIM-LEAN and the evolution of QS services. Section $C$ is to identify the challenges, and barriers quantity surveyors might encounter in shifting from traditional QS service to the third generation of QS services triggered by BIM-LEAN. Section D gathers feedback regarding the strategies in implementing the QS 3.0 in quantity surveying services. Likert Scales 1-5 were used in the questionnaire survey and the Relative Importance Index (RII) calculated by Eq. 1 was derived for each factor as adopted from Yap and Lock (2017) and Yap and Skitmore (2018).

$R I I=\frac{5(N 1)+4(N 2)+3(N 3)+2(N 4)+1(N 5)}{5(N 1+N 2+N 3+N 4+N 5)}$

where $N 1$ is the number of respondents who answered "strongly agree," and N5 is the number of respondents who answered, "strongly disagree." Alpha Cronbach calculated in Eq. 2 was used to measure the reliability, and the values above 0.70 were considered acceptable while values above 0.80 were preferable.

$\alpha=\frac{n}{n-1}\left(1-\frac{\sum V_{i}}{V_{\text {test }}}\right)$

where " $n$ " is the number of questions; " $V$ " is the variance of scores on each question, $i=1,2,3, \ldots, n$; and "V-test" is the total variance of overall scores (not in percentage) on the overall test. In addition to the reliability analysis of the questionnaire, it is also necessary to analyze the validity of the questionnaire. In the structural validity test of questionnaires, the most commonly used method is factor analysis, which tests the internal logical structure of the items through factor analysis. In the structure validity test, there are two indicators used to test the aggregate validity, namely the average variance extraction value (AVE) and the combined reliability (CR). When the AVE is above 0.5 and the CR is above 0.7 , the aggregate validity is indicated. Before that, KMO and Bartlett sphericity tests should be performed. When the KMO value is above 0.6 and the $p$ value corresponding to Bartlett sphericity is less than 0.05 , the data are suitable for factor analysis (see Sect. 4 for specific numerical analysis).

The one-way independent ANOVA has a nonparametric counterpart called the Kruskal-Wallis test which was used to determine the extent to which the effect of an independent variable to a major component or to compare two or more populations in a completely randomized design using Eq. 3 (Yap and Lock 2017).

$H=\frac{12}{n(n+1)} \sum \frac{T_{i}^{2}}{n_{i}}-3(n+1)$

where " $n$ " = number of sample; " $n_{i}$ " = sample size of the assigned number, $i=1,2,3, \ldots, k$; " $T_{i}$ " $=$ sum of rank for the 
assigned sample, $i=1,2,3, \ldots, k$. Mann-Whitney $\mathrm{U}$ test was conducted after the Kruskal-Wallis test to measure differences among participants, which was considered the nonparametric alternative to the independent t-test. Principal components analysis (PCA) as a variable-reduction technique was conducted to reduce a larger set of independent variables into a smaller set of "artificial" variables also known as principal components, wherein this study it was used in clustering the challenges and strategies in implementing BIMLEAN in modern quantity surveying services. The partial least squares structural equation modeling technique through SmartPLS3.0 visually examined the correlation among variables. PLS-SEM model validation includes R-squared $\left(R^{2}\right)$ and path coefficient significance testing. In this study, $R^{2}$ was used to verify the explanatory power of the model. $R^{2}$ is an important basis for testing model quality and represents the explanatory ability of measured variables to latent variables. Bootstrapping was used to test the significance of the path coefficients on the PLS-SEM, and the $d f$ and $p$ values of the factors were measured, respectively (see Sect. 4 for specific numerical analysis). The demographic characteristics of the respondents are summarized in Table 1.

Table 1 Demographics of respondents

\begin{tabular}{|c|c|c|c|}
\hline Nos. & Demographic characteristics & $\begin{array}{l}\text { Frequency } \\
(n=x)\end{array}$ & Percentage \\
\hline \multirow[t]{3}{*}{1} & Gender & & \\
\hline & Male & 53 & $52.0 \%$ \\
\hline & Female & 49 & $48.0 \%$ \\
\hline \multirow[t]{5}{*}{2} & Age & & \\
\hline & $20-29$ & 39 & $38.2 \%$ \\
\hline & $30-39$ & 38 & $37.3 \%$ \\
\hline & $40-49$ & 16 & $15.7 \%$ \\
\hline & 50 and above & 9 & $8.8 \%$ \\
\hline \multirow[t]{7}{*}{3} & Position In company & & \\
\hline & Director of company & 11 & $10.8 \%$ \\
\hline & Project manager & 14 & $13.7 \%$ \\
\hline & Senior QS & 28 & $27.5 \%$ \\
\hline & Assistant QS & 18 & $17.6 \%$ \\
\hline & Junior QS & 24 & $23.5 \%$ \\
\hline & Others & 7 & $6.9 \%$ \\
\hline \multirow[t]{5}{*}{4} & Working experience & & \\
\hline & More than 15 years & 35 & $34.4 \%$ \\
\hline & $11-15$ years & 29 & $28.4 \%$ \\
\hline & $5-10$ years & 23 & $22.5 \%$ \\
\hline & Less than 5 years & 15 & $14.7 \%$ \\
\hline \multirow[t]{4}{*}{5} & Status of registration & & \\
\hline & Registered QS & 44 & $43.1 \%$ \\
\hline & Registered graduate QS & 39 & $38.2 \%$ \\
\hline & Non-registered QS & 19 & $18.7 \%$ \\
\hline
\end{tabular}

Out of 102 respondents, 53 were male (52.0\%) and 49 were female $(48.0 \%)$. There were 39 or $38.2 \%$ respondents between 20 to 29 years old, followed by 38 or $37.3 \%$ between 30 to 39 years old, 16 or $15.7 \%$ between 40 and 49, and 9 or $8.8 \%$ more than 50 years old. The respondents' positions were 11 or $10.8 \%$ company directors, 14 or $13.7 \%$ project managers, 28 or $27.5 \%$ senior QS, 18 or $17.6 \%$ assistant QS, 24 or $23.5 \%$ junior QS, and 7 or $6.9 \%$ others. There were 35 or $34.4 \%$ respondents who have more than 15 years of working experience, followed by 29 or $28.4 \% 11-15$ years, 23 or $22.5 \% 5-10$ years, and 15 or $14.7 \%$ less than 5 years. There were 44 or $43.1 \%$ registered QS and 39 or $38.2 \%$ registered graduate QS, and 19 or $18.7 \%$ non-registered QS.

\section{Data Analysis and Results}

The Cronbach's coefficient alpha computed is 0.795 , which is higher than the 0.70 value needed for satisfactory reliability analysis (Yap and Skitmore 2018). The CR is 0.865, and the AVE is 0.649 . The majority of the respondents (69\%) prefer working through the BIM-LEAN method while the other $31 \%$ still favors traditional paper-based methods in QS practices. Among the $31 \%$ paper-based supporters, $87 \%$ have been practicing QS for more than 15 years where the traditional methods have already created a "path dependence" effect on their way of processing taking-off. BIMLEAN capabilities and benefits from A1 to A10 are ranked in Table 2 in descending order.

The most significant ability of BIM-LEAN to QS services is A4: Eases to conduct cost appraisal and preliminary cost plan detail \& accurately, which is a cost management function at the feasibility stage. QSs take a weighty role in this decisive stage to provide professional advice to the project's clients based on the initial cost appraisal to determine the suitability to run the project. BIM-LEAN helps to extract

Table 2 BIM-LEAN capabilities and benefits ranking

\begin{tabular}{lc}
\hline Statements & Ranking \\
\hline $\begin{array}{l}\text { A4: Eases to conduct cost appraisal and preliminary cost } \\
\text { plan detail and accurately }\end{array}$ & 1 \\
A1: Improves visualization to design drawing & 2 \\
A8: Assists in cost estimation and cost checking accurately & 3 \\
A7: Conducts quantities take-off automatically & 4 \\
A9: Prepares bill of quantities easily & 5 \\
A10: Improves productivity and speed of delivery & 6 \\
A2: Improves communication among parties in project & 7 \\
A3: Increases coordination of construction documents & 7 \\
A6: Performs clash detection and clash analysis & 9 \\
A5: Faster the speed of design deciding & 10 \\
\hline
\end{tabular}


geometric data which available in the model in order to help QSs in generating preliminary cost estimates.

The second-ranked capability is A1: Improves visualization to design drawing. Visualization function from BIMLEAN enhances QSs' understanding of the design especially for complex buildings which assists in producing high accurately costing at an early stage of the project. The third most desired benefit is A8: Assists in cost estimation and cost checking accurately. As all the detailed information provided in the model, it helps QSs in doing cost estimating works such as materials cost, and labor costs. By clicking the elements given in the model, it will show us all the information such as quantities of materials, types of materials, material suppliers, and number of workers required. Conducts quantities take-off automatically (A7) and prepare a bill of quantities easily (A9) were ranked fourth and fifth, respectively. The taking-off task is the major task QSs required to conduct before moving to other tasks in QS practices. This task usually takes up QSs' a lot of time in focusing on the design and measuring item by item via drawing. By using BIM-LEAN, QSs enable to extraction of the quantities directly from the model and subsequently used for BQ preparation. It is worth noting that A5: Faster the speed of design deciding is perceived as the least critical benefit of BIM-LEAN. During the design stage, clients will request different design options from the architect and QSs are required to do accurate cost estimation to enable clients to conduct evaluation and comparison. Despite the last standing, BIM-LEAN supports QSs to analyze and evaluate through accurate cost estimation for alternative designs and provide advice and feedback to clients immediately.

\subsection{Challenges in BIM-LEAN Interaction in Modern QS Practices}

Table 3 shows the relative importance index (RII) and ranking for each challenge in integrating BIM-LEAN in QS practices. A close examination of Table 4 reveals that the top five most important challenges are (1) C11: Financial considerations (RII $=0.846)$, (2) $\mathrm{C} 1$ : Lack of technical expertise in BIM-LEAN (RII =0.806), (3) C6: Lack of motivation and guidance from top management $(\mathrm{RII}=0.802)$, (4) C4: Behavior and attitude of peoples to learn something new and challenge technology $(\mathrm{RII}=0.772),(5) \mathrm{C} 9$ : Lack of knowledge, understanding, and skill about BIM-LEAN $(\mathrm{RII}=0.768)$. Cost and proficiency issues are the major barriers to the implementation of BIM-LEAN.
Table 3 Relative Importance Index (RII) and ranking of challenges/barriers

\begin{tabular}{|c|c|c|c|c|c|c|c|}
\hline \multirow[t]{2}{*}{ Challenges in adopting BIM-LEAN in QS practices } & \multicolumn{5}{|c|}{ Rating (nos.) } & \multirow[t]{2}{*}{ RII } & \multirow[t]{2}{*}{ Rank } \\
\hline & 1 & 2 & 3 & 4 & 5 & & \\
\hline C11: Financial considerations & 2 & 2 & 21 & 22 & 55 & 0.846 & 1 \\
\hline C1: Lack of technical expertise in BIM-LEAN & 2 & 3 & 23 & 35 & 39 & 0.806 & 2 \\
\hline C6: Lack motivation and guidance from top management & 2 & 9 & 13 & 39 & 39 & 0.802 & 3 \\
\hline $\begin{array}{l}\text { C4: Behavior and attitude of peoples to learn something new and } \\
\text { challenge technology }\end{array}$ & 5 & 5 & 13 & 54 & 25 & 0.772 & 4 \\
\hline C9: Lack knowledge, understanding and skill about BIM-LEAN & 3 & 2 & 16 & 68 & 13 & 0.768 & 5 \\
\hline C12: Lack of demand from clients & 2 & 2 & 34 & 41 & 23 & 0.758 & 6 \\
\hline C5: Organization refused to change business way & 2 & 9 & 28 & 40 & 23 & 0.744 & 7 \\
\hline C8: Lack training, education and awareness programs & 3 & 11 & 17 & 56 & 15 & 0.734 & 8 \\
\hline C7: Lack government direction and standard guidelines & 3 & 6 & 30 & 49 & 14 & 0.728 & 9 \\
\hline C10: Lack of compatibility software & 3 & 25 & 39 & 22 & 13 & 0.636 & 10 \\
\hline $\begin{array}{l}\text { C2: Technical difficulties, e.g.: poor internet connections, limited } \\
\text { access and poor network security }\end{array}$ & 14 & 36 & 33 & 13 & 6 & 0.524 & 11 \\
\hline C3: BIM-LEAN will grab QS's job & 59 & 24 & 10 & 5 & 4 & 0.348 & 12 \\
\hline
\end{tabular}

Table 4 Kruskal-Wallis test for challenges/barriers

\begin{tabular}{lllllllllllll}
\hline \multicolumn{1}{c}{$\mathrm{C} 1$} & $\mathrm{C} 2$ & $\mathrm{C} 3$ & $\mathrm{C} 4$ & $\mathrm{C} 5$ & $\mathrm{C} 6$ & $\mathrm{C} 7$ & $\mathrm{C} 8$ & $\mathrm{C} 9$ & $\mathrm{C} 10$ & $\mathrm{C} 11$ & $\mathrm{C} 12$ \\
\hline Test statistics & a,b & & & & & & & & & & & \\
Chi-square & .679 & 5.223 & 23.695 & 17.454 & 4.941 & 2.109 & 4.734 & 3.151 & 1.324 & 16.537 & 9.900 & 17.725 \\
$d f$ & 3 & 3 & 3 & 3 & 3 & 3 & 3 & 3 & 3 & 3 & 3 & 3 \\
Asymp. sig & .878 & .156 & .000 & .001 & .176 & .550 & .192 & .369 & .723 & .001 & .019 & .001 \\
\hline
\end{tabular}

${ }^{a}$ Kruskal Wallis test

${ }^{\mathrm{b}}$ Grouping variable: working experience 
Table 4 provides Kruskal-Wallis One-Way ANOVA test for a " $k$ " independent sample to determine whether the perception of respondents on each challenge is related to their working experience, where five out of twelve variables are of statistically significant differences as the significant values are less than 0.05 indicating that the challenges perceived is affected by their working experience. These four measures are C3: Replace the role of Quantity Surveyor profession $(\times 2=23.695, p=0.000<0.05) ; C 4$ : Behavior and attitude of peoples to learn something new and challenge technology $(\times 2=17.454, p=0.001<0.05)$; C10: Lack of compatibility software $(\times 2=16.537, p=0.001<0.05)$; C11: Financial considerations $(\times 2=9.900, p=0.019<0.05)$ and $\mathrm{C} 12$ : Lack of demand from clients $(\times 2=17.725, p=0.001<0.05)$.

Figure 1 exhibits the analysis using Partial Least Square (PLS) Structural Equation Modeling (SEM) between these challenges and working experiences, where each circle represents one coefficient $R^{2}$ of determination for variables. $R^{2}$ above 0.75 denotes substantial; 0.50 moderate; and 0.25 weak. The $R^{2}$ values for all variables are below 0.25 indicating that working experience does not explain the variance in the variables involved. The inner model suggests the effect of one variable on another variable. In this case, working experience is used as the indicator, where "working experience" and "C12: Lack of demand from clients by using BIM-LEAN in project" are statistically significant where the coefficient 0.322 is the highest among all variables. Bootstrapping is then used to check the structural path significance. The coefficient values greater than 1.96 is considered significant. There are five variables with values higher than 1.96 namely: C3: Replace the role of Quantity

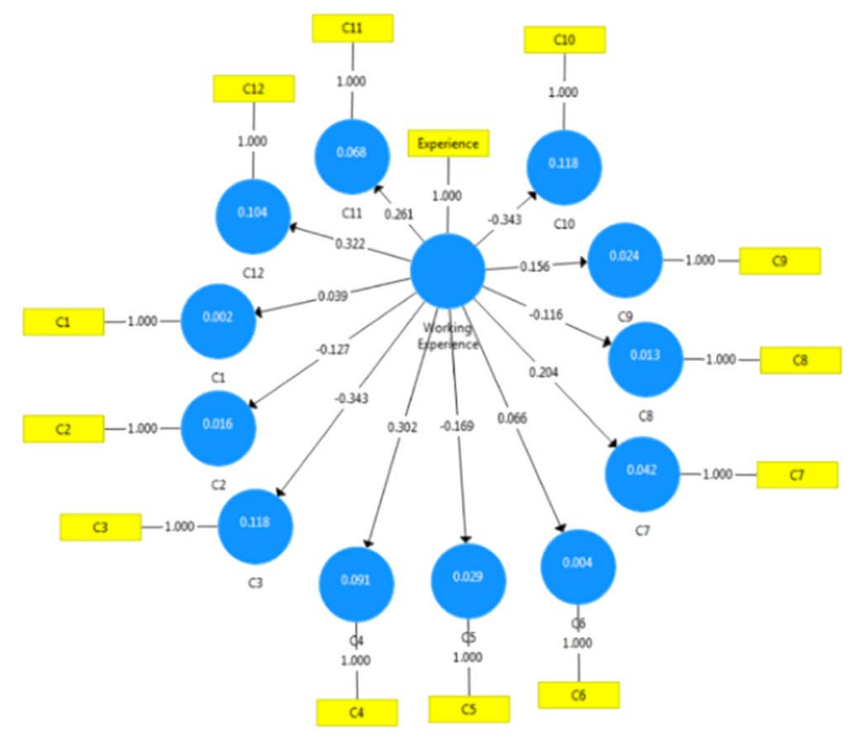

(a)
Surveyor profession (4.494> 1.96); C4: Behavior and attitude of peoples to learn something new and challenge technology (2.956> 1.96); C10: Lack of compatibility software (3.770 > 1.96); C11: Financial considerations (3.031 > 1.96) and C12: Lack of demand from clients $(3.762>1.96)$.

Principal components analysis (PCA) is further conducted on these 12 challenges/ barriers in integrating BIM-LEAN in QS practices. Inspection of the correlation matrix reveals that all variables have at least one correlation coefficient greater than 0.3. The overall Kaiser-Meyer-Olkin (KMO) measure is 0.792 with individual KMO measures greater than 0.5 . Bartlett's test of sphericity with value $(p=0.000)$ is statistically significant $(p<0.001)$, indicating that the data are factorable. Table 5 shows the communality of each variable's variance accounted by PCA expressed in percentage. Table 6 presents the total variance explained from PCA, where three components that have eigenvalues explained $35.756 \%, 18.125 \%$, and $10.629 \%$ of the total variance,

Table 5 Communalities from PCA for challenges

\begin{tabular}{|c|c|c|c|c|c|}
\hline Challenges & Initial & Extraction & Challenges & Initial & Extraction \\
\hline \multicolumn{6}{|c|}{ Communalities } \\
\hline $\mathrm{C} 1$ & 1.000 & 0.592 & C7 & 1.000 & 0.297 \\
\hline $\mathrm{C} 2$ & 1.000 & 0.608 & $\mathrm{C} 8$ & 1.000 & 0.779 \\
\hline C3 & 1.000 & 0.607 & C9 & 1.000 & 0.480 \\
\hline $\mathrm{C} 4$ & 1.000 & 0.651 & $\mathrm{C} 10$ & 1.000 & 0.680 \\
\hline $\mathrm{C} 5$ & 1.000 & 0.738 & $\mathrm{C} 11$ & 1.000 & 0.758 \\
\hline C6 & 1.000 & 0.796 & $\mathrm{C} 12$ & 1.000 & 0.754 \\
\hline
\end{tabular}

Extraction method: principal component analysis

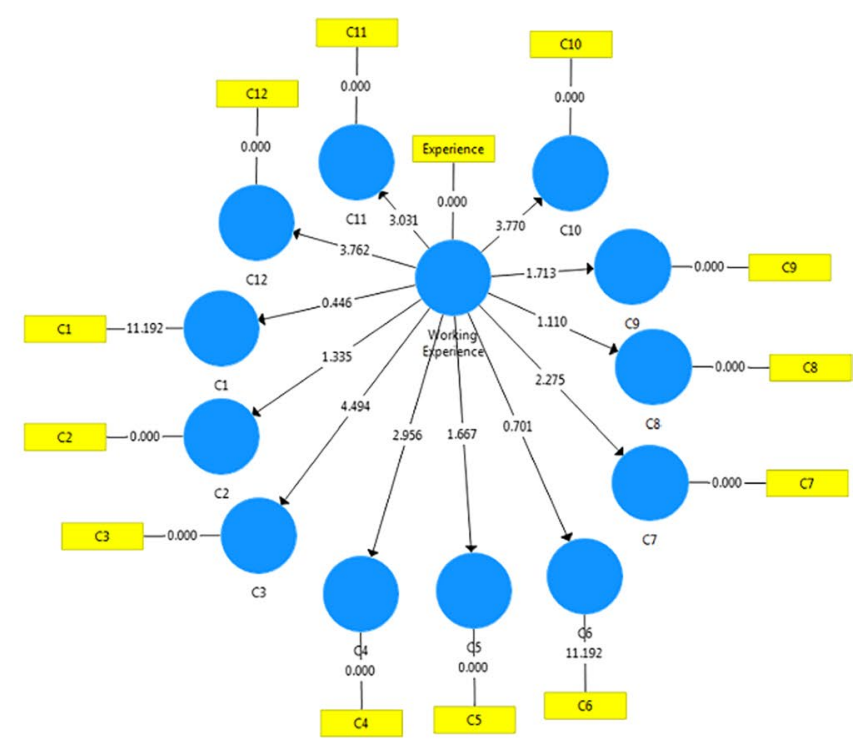

(b)

Fig. 1 a PLS algorithm model and $\mathbf{b}$ bootstrapping for challenges 
Table 6 Total variance explained from PCA for challenges

\begin{tabular}{|c|c|c|c|c|c|c|c|c|c|}
\hline \multirow[t]{2}{*}{ Components } & \multicolumn{3}{|c|}{ Initial eigenvalues } & \multicolumn{3}{|c|}{ Extraction sums of squared loadings } & \multicolumn{3}{|c|}{ Rotation sums of squared loadings } \\
\hline & Total & $\%$ of Variance & Cumulative $\%$ & Total & $\%$ of Variance & Cumulative $\%$ & Total & $\%$ of Variance & Cumulative $\%$ \\
\hline 1 & 4.291 & 35.756 & 35.756 & 4.291 & 35.756 & 35.756 & 2.946 & 24.549 & 24.549 \\
\hline 2 & 2.175 & 18.125 & 53.880 & 2.175 & 18.125 & 53.880 & 2.687 & 22.392 & 46.941 \\
\hline 3 & 1.275 & 10.629 & 64.509 & 1.275 & 10.629 & 64.509 & 2.108 & 17.568 & 64.509 \\
\hline 4 & .879 & 7.329 & 71.838 & & & & & & \\
\hline 5 & .743 & 6.192 & 78.030 & & & & & & \\
\hline 6 & .565 & 4.704 & 82.734 & & & & & & \\
\hline 7 & .494 & 4.113 & 86.847 & & & & & & \\
\hline 8 & .426 & 3.553 & 90.400 & & & & & & \\
\hline 9 & .380 & 3.163 & 93.564 & & & & & & \\
\hline 10 & .309 & 2.571 & 96.134 & & & & & & \\
\hline 11 & .251 & 2.093 & 98.228 & & & & & & \\
\hline 12 & .213 & 1.772 & 100.000 & & & & & & \\
\hline
\end{tabular}

Extraction method: principal component analysis

respectively. Visual inspection of the scree plot shown in Fig. 2 indicates that three components should be retained as the eigenvalue greater than 1.0 before the inflection point of the graph. The inflection point is the point where the graph begins to level out and subsequent components add little to the total variance. Hence, three components are retained, satisfying the interpretability criterion. The three-component solution explained $64.509 \%$ of the total variance.

A Varimax orthogonal rotation is employed to aid interpretability in Fig. 3 where the rotated solution exhibited "simple structure." Component 1 consists of 5 challenges such as $\mathrm{C} 1, \mathrm{C} 5, \mathrm{C} 6, \mathrm{C} 7$, and $\mathrm{C} 8$ sharing one similarity in terms of social and cultural issues. In order to implement
BIM-LEAN in QS practices, social issues take a significant role among parties such as organization, government, and related authorities. C5: Organization refused to change business process to suit new technology, C6: Lack of motivation and guidance from top management, and $\mathrm{C} 1$ : Lack of BIM-LEAN technical expertise in the organization is related to social issues within organizations. If an organization is reluctant to accept BIM-LEAN technology, it does typically not hire BIM-LEAN experts or initiate motivation and guidance to employees. C7: Lack of government direction and standard guidelines is related to the process of government in which government must take actions to produce BIMLEAN standard guidelines to ensure successful adoption of
Fig. 2 Scree plot test from PCA for challenges

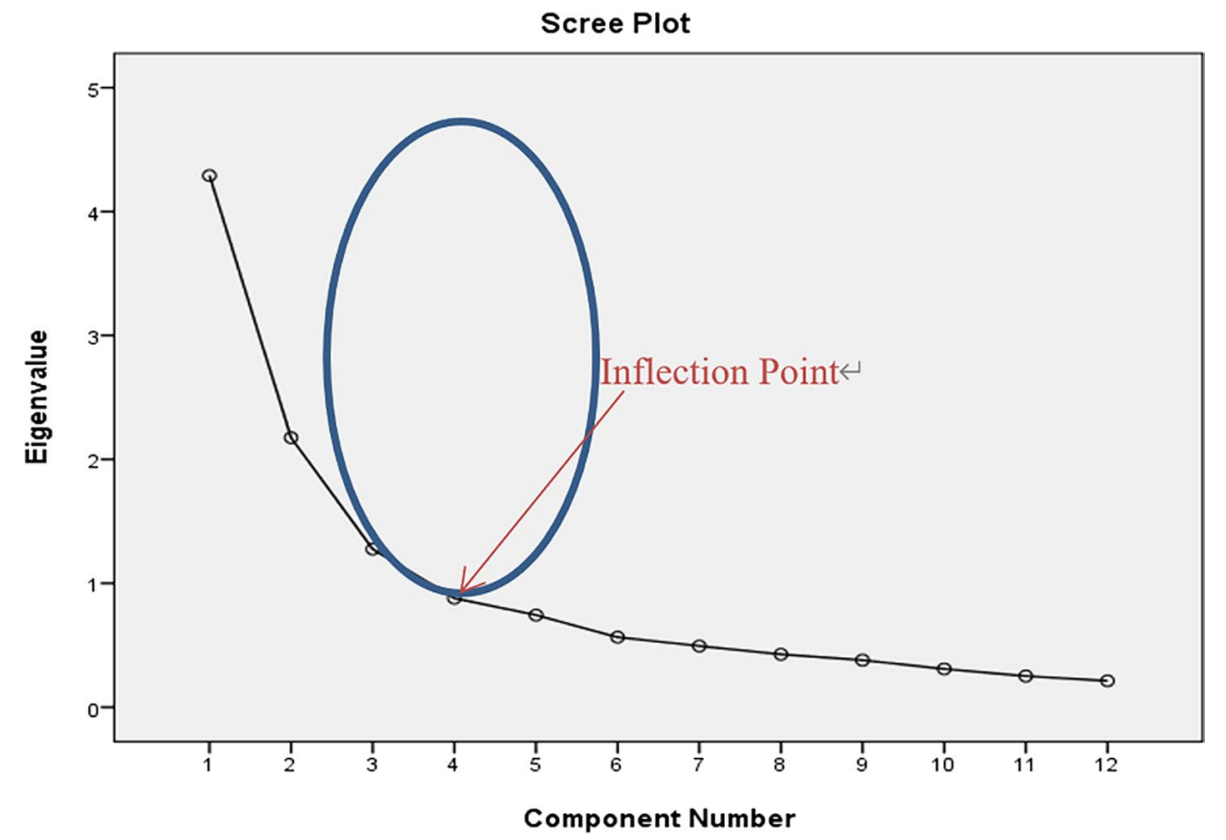




\section{Component Plot in Rotated Space}

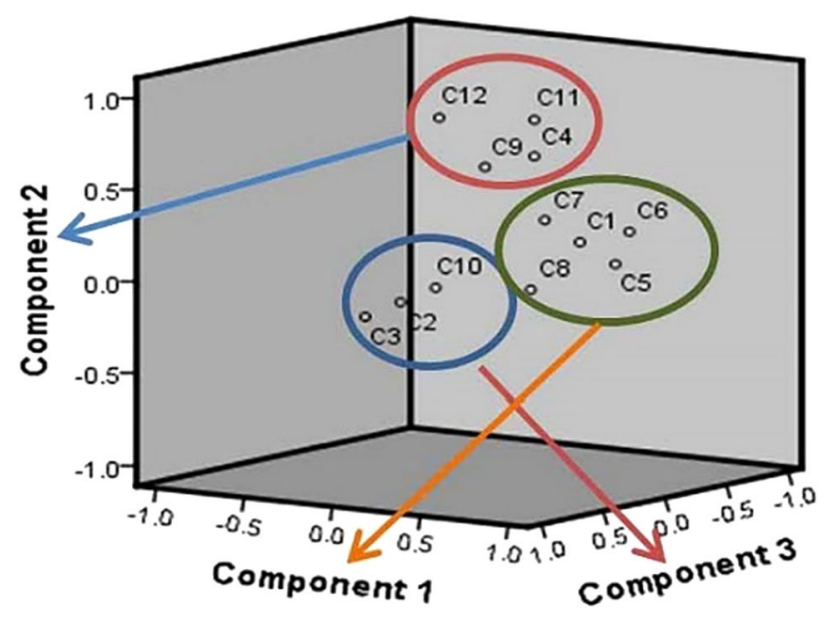

Fig. 3 Component plot in rotated space from PCA for challenges

BIM-LEAN in QS practices and revolution. It also requires related authorities to organize training, seminar, and awareness programs regarding BIM-LEAN, which is associated with C8: Lack of training, education and awareness programs. Furthermore, C4, C9, C11, and C12 are grouped as Component 2, which is challenges regarding human factors. Finally, Component 3 comprises C2, C3, and C10 related to technical factors.

\subsection{Potential Strategies for BIM-LEAN Interaction in Sustainable Development on QS Services}

The Cronbach's coefficient alpha for this dataset is 0.915 which also satisfies the internal consistency criterion (Alufohai 2013). The CR is 0.826 , and the AVE is 0.623. Table 7 presents the relative importance index (RII) and ranking of strategies for QS 3.0 adoption. The top five most important strategies are (1) S7: Leadership and motivation from senior management (RII $=0.840)$, (2) S10: Increase the number of BIM-LEAN training to staff (RII =0.834), (3) S6: Hire BIM-LEAN experts in an organization $(\mathrm{RII}=0.818),(4) \mathrm{S} 1$ : Promotion and awareness programs (RII $=0.814)$, (5) S8: Requirement staffs to be BIM-LEAN competent and provide extra incentives $(\mathrm{RII}=0.786)$. Top management commitment is seen as the most effective strategy as a top-down approach can reduce the resistance from people to change the new working culture and nurture the desired supportive culture. BIM-LEAN training for staff can improve their understanding and skill toward using BIM-LEAN and at the same time increase their confidence to commit to new working culture. Lack of proper training to staff contribute to an organization's failure to reap the competitive edge of implementing new technology. The level and type of training should be based on the needs of the individuals within that organization. It is difficult to ensure that each individual in the company can master the necessary understanding and skills toward new technology. Thus, the organization should form a BIM-LEAN expert group to troubleshoot the problems encountered and share the BIM-LEAN knowledge with one another in the company.

Table 8 shows the results of Kruskal-Wallis One-Way ANOVA test for a $\mathrm{k}$ independent sample to determine whether the perceptions of respondents on strategies were related to working experience. Two out of eleven strategies were affected by working experience namely: S1: Promotion and awareness programs $(\times 2=8.677, p=0.034<0.05)$ and S9: Improve in technical support $(\times 2=8.689$, $p=0.034<0.05$ ).

Figure 4 exhibits the PLS algorithm model and bootstrapping where "working experience" and "S1: Promotion and awareness programs" are highly correlated indicated by the highest coefficient value at 0.275 . Two of the variables with

Table 7 Relative Importance Index (RII) and ranking of strategies/actions

\begin{tabular}{|c|c|c|c|c|c|c|c|}
\hline \multirow[t]{2}{*}{ Strategies in BIM-LEAN interaction in QS practices } & \multicolumn{5}{|c|}{ Rating (nos.) } & \multirow[t]{2}{*}{ RII } & \multirow[t]{2}{*}{ Rank } \\
\hline & 1 & 2 & 3 & 4 & 5 & & \\
\hline S7: Leadership and motivation from senior management & 3 & 3 & 9 & 42 & 45 & 0.840 & 1 \\
\hline S10: Increase number of BIM-LEAN training to staff & 4 & 2 & 8 & 46 & 42 & 0.834 & 2 \\
\hline S6: Hire BIM-LEAN experts in an organization & 5 & 5 & 11 & 35 & 46 & 0.818 & 3 \\
\hline S1: Promotion and awareness programs & 4 & 2 & 13 & 46 & 37 & 0.814 & 4 \\
\hline S8: Requirement staffs to be BIM-LEAN competent and provide extra incentives & 3 & 2 & 12 & 66 & 19 & 0.786 & 5 \\
\hline S5: Development of BIM-LEAN department in company & 5 & 2 & 16 & 54 & 25 & 0.778 & 6 \\
\hline S11: Continuous investment in BIM-LEAN & 4 & 2 & 24 & 59 & 13 & 0.748 & 7 \\
\hline S4: Encourage clients in using BIM-LEAN in projects & 4 & 2 & 29 & 59 & 8 & 0.728 & 8 \\
\hline S2: Standardize procedures and enforcement by government & 4 & 3 & 32 & 52 & 11 & 0.724 & 9 \\
\hline S3: Research collaboration and curriculum design for university students & 4 & 6 & 36 & 39 & 17 & 0.716 & 10 \\
\hline S9: Improve in technical support & 3 & 16 & $42 d$ & 30 & 11 & 0.658 & 11 \\
\hline
\end{tabular}


Table 8 Kruskal-Wallis test for strategies/actions

\begin{tabular}{llllllllllll}
\hline \multicolumn{1}{c}{ S1 } & S2 & S3 & S4 & S5 & S6 & S7 & S8 & S9 & S10 & S11 \\
\hline Test statistics $^{\mathrm{a}, \mathrm{b}}$ & & & & & & & & & & & \\
Chi-square & 8.677 & 4.262 & 3.151 & 7.408 & 3.292 & 3.270 & 4.999 & 3.074 & 8.689 & 2.354 & 3.384 \\
$d f$ & 3 & 3 & 3 & 3 & 3 & 3 & 3 & 3 & 3 & 3 & 3 \\
Asymp. sig & .034 & .235 & .369 & .060 & .349 & .352 & .172 & .380 & .034 & .502 & .336 \\
\hline
\end{tabular}

${ }^{a}$ Kruskal Wallis test

${ }^{\mathrm{b}}$ Grouping variable: working experience

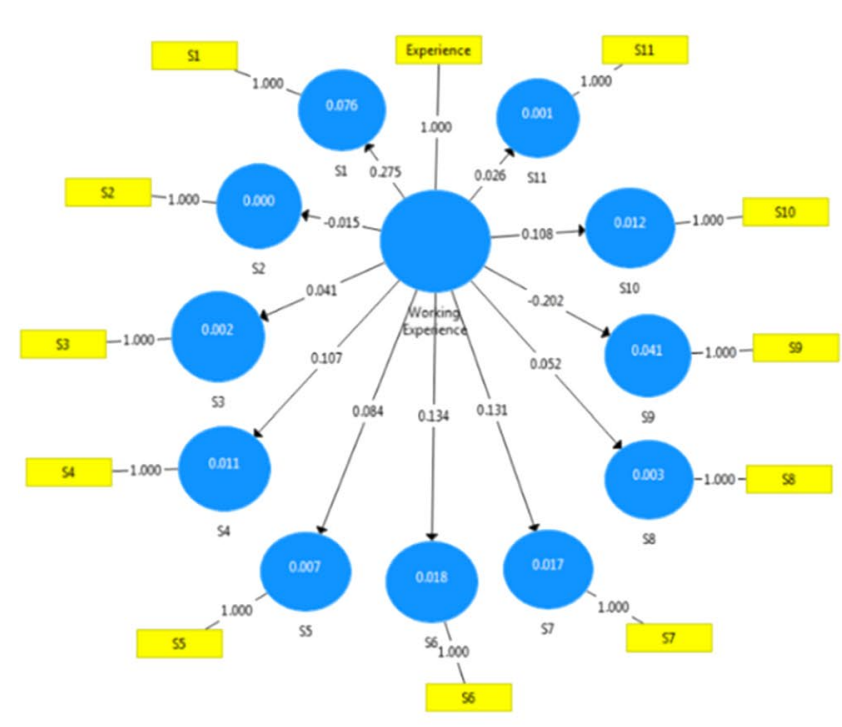

(a)

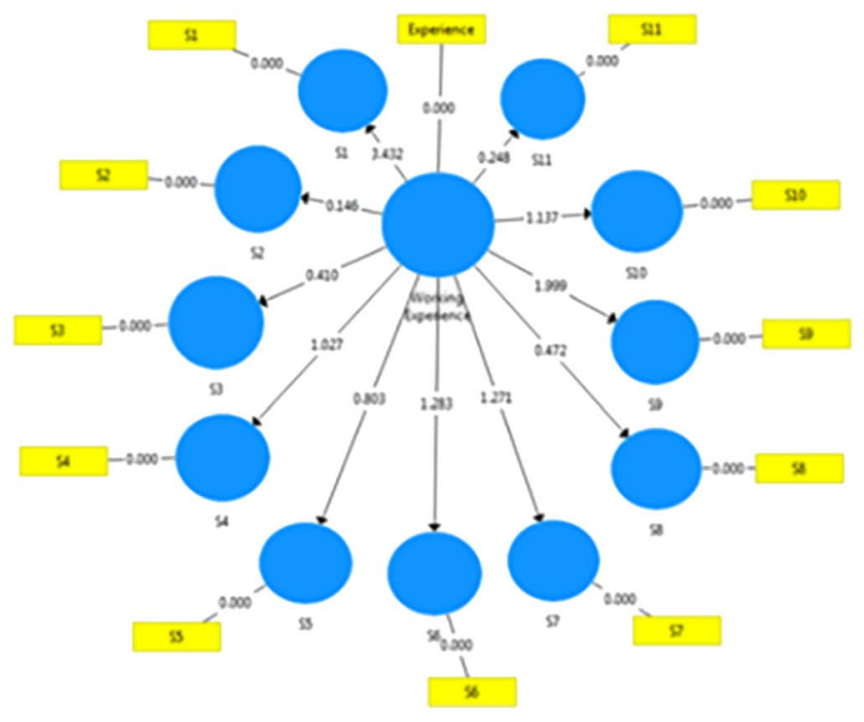

(b)

Fig. 4 a PLS algorithm model and $\mathbf{b}$ bootstrapping for strategies

values more than 1.96 are S1: Promotion and awareness programs $(3.432>1.96)$ and S9: Improve in technical support $(1.999>1.96)$ indicating a strong association in between.

Table 9 shows the principal component analysis (PCA) conducted on the 11 potential strategies in implementing BIM-LEAN in modern QS practices. Inspection of the correlation matrix shows that all variables have at least one correlation coefficient greater than 0.3 . The overall Kaiser-Meyer-Olkin (KMO) measure is 0.873 with individual KMO measures greater than 0.5 . Bartlett's test of sphericity with value $(p=0.000)$ is statistically significant $(p<0.001)$ indicating a factorability. Total variance explained from PCA reveals two components with eigenvalues greater than 1.0 explaining $55.480 \%$ and $11.407 \%$ of the total variance, respectively.

Visual inspection of the scree plot in Fig. 5 indicates that two components should be retained as the eigenvalue greater than 1.0 before the inflection point of the graph. The twocomponent solution explained $66.887 \%$ of the total variance.

A Varimax orthogonal rotation is employed to aid interpretability as shown in Fig. 6. The rotated solution exhibited "simple structure" where Component 1 is most highly correlated with S7, S6, S1, S10, S5, and S8 while Component 2 is most highly related to $\mathrm{S} 9, \mathrm{~S} 11, \mathrm{~S} 4, \mathrm{~S} 3$, and $\mathrm{S} 2$.

\subsection{Correlation Among Working Experience, Challenges, Strategies and Decision Making}

Correlations among working experience, challenges, strategies, and decision making toward BIM-LEAN interaction in modern QS services are illustrated in Fig. 7, where the $R^{2}$ value of variable "Challenges" at 0.384 is the highest among three variables indicating its significance toward working experience. However, it does not exert a strong effect on the independent variable since the value is only near to the moderate. Different working experiences could lead to different perspectives toward the challenges in implementing BIM-LEAN in modern QS services. For example, people with longer working experience tended to disagree that "BIM-LEAN will replace the role of the QS Production" while people with shorter experience tended to agree. The $R^{2}$ values of variables "Strategies" and "Decision Making" 
Table 9 Total variance explained from PCA for strategies

\begin{tabular}{|c|c|c|c|c|c|c|c|c|c|}
\hline \multirow[t]{2}{*}{ Components } & \multicolumn{3}{|c|}{ Initial eigenvalues } & \multicolumn{3}{|c|}{ Extraction sums of squared loadings } & \multicolumn{3}{|c|}{ Rotation sums of squared loadings } \\
\hline & Total & $\%$ of Variance & Cumulative \% & Total & $\%$ of Variance & Cumulative $\%$ & Total & $\%$ of Variance & Cumulative $\%$ \\
\hline 1 & 6.103 & 55.480 & 55.480 & 6.103 & 55.480 & 55.480 & 4.403 & 40.029 & 40.029 \\
\hline 2 & 1.255 & 11.407 & 66.887 & 1.255 & 11.407 & 66.887 & 2.954 & 26.858 & 66.887 \\
\hline 3 & .858 & 7.796 & 74.683 & & & & & & \\
\hline 4 & .671 & 6.097 & 80.780 & & & & & & \\
\hline 5 & .645 & 5.860 & 86.640 & & & & & & \\
\hline 6 & .393 & 3.577 & 90.217 & & & & & & \\
\hline 7 & .296 & 2.693 & 92.910 & & & & & & \\
\hline 8 & .268 & 2.441 & 95.350 & & & & & & \\
\hline 9 & .197 & 1.790 & 97.141 & & & & & & \\
\hline 10 & .175 & 1.593 & 98.733 & & & & & & \\
\hline 11 & .139 & 1.267 & 100.000 & & & & & & \\
\hline
\end{tabular}

Extraction method: principal component analysis

Fig. 5 Scree plot test from PCA for strategies

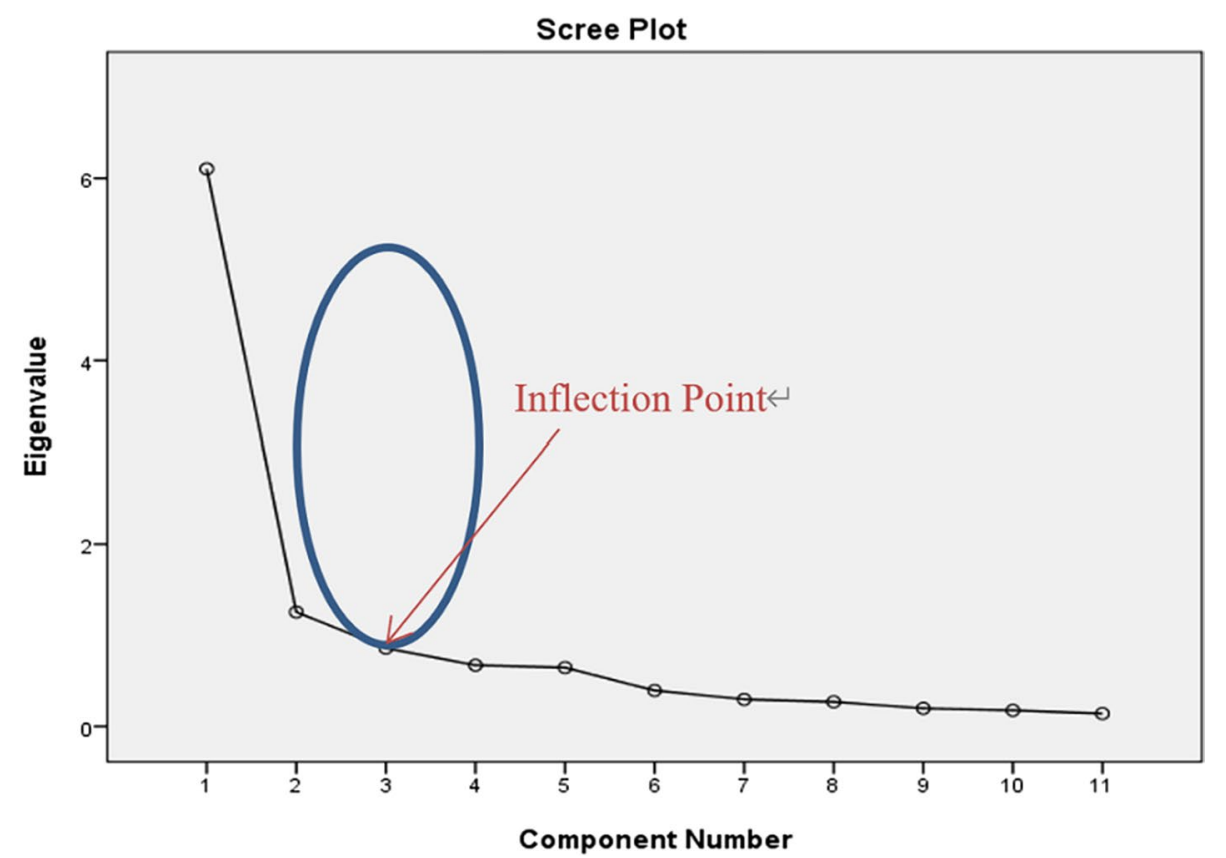

toward working experience at 0.058 and 0.126 , respectively, indicate a very weak association.

\subsection{System Dynamics Model for BIM-LEAN Interaction in Sustainable QS Production Development}

A System Dynamics model for BIM-LEAN interaction in modern QS services was developed based on the survey analysis as visualized in Fig. 8. Driven by modern technological advancements such as BIM-LEAN in QS practices, quantity surveyors gained potentials in further improving their roles effectively and efficiently. Traditional roles of QS only include: measurement, preparation of bills of quantities, estimating and cost planning, procurement advice, tender documentation, and cost control on construction as well as preparation of contractual claims and final accounts. Computer technology-enabled new functions of QS such as conducting life cycle costing, value and quality management, project management, facilities management, risk analysis, and solving contractual disputes. BIM-LEAN technology could further enhance QS roles in automated measurement and quantification, environmental and sustainability analysis, facilities management, quality management, and legal services.

The challenges related to financial issues such as hardware and software cost and training cost could be more effective to small-and-medium-sized QS firms. Lack of 
Fig. 6 Component plot in rotated space from PCA for strategies

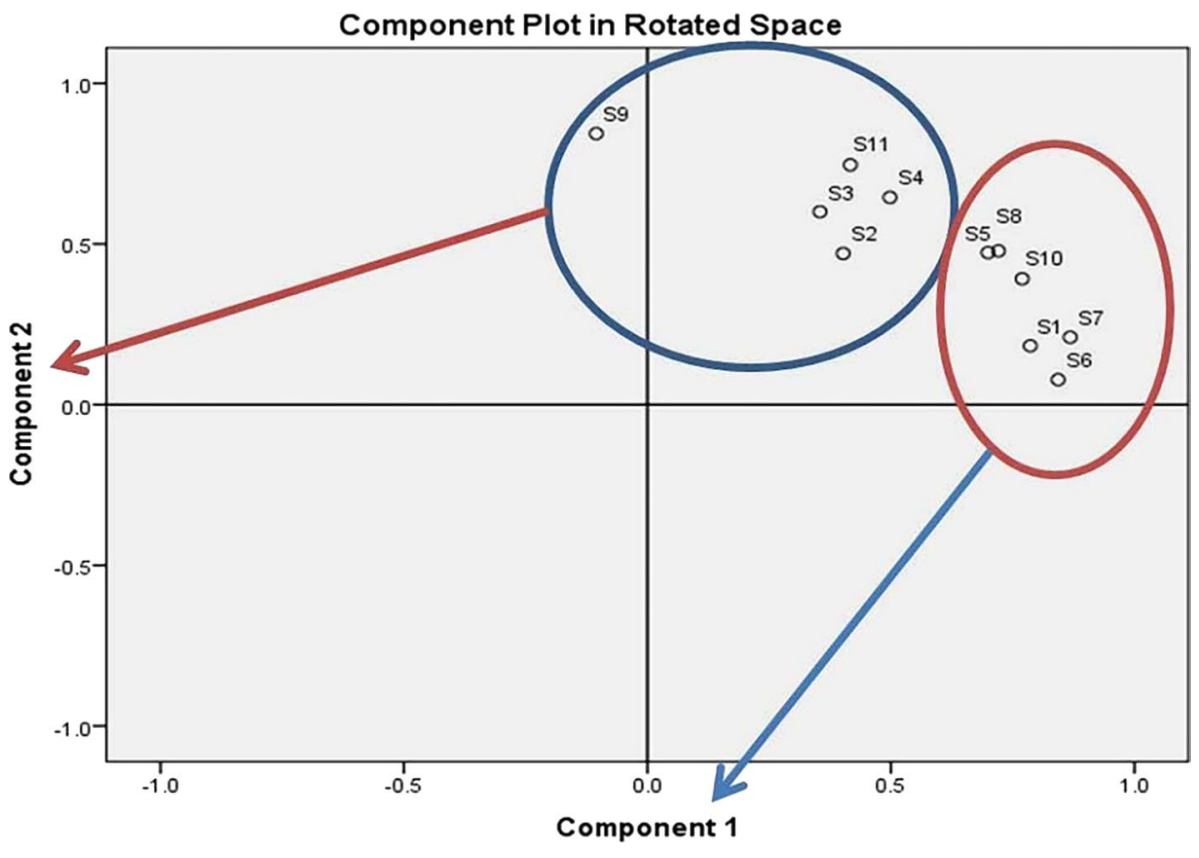

Fig. 7 PLS algorithm on correlation among variables

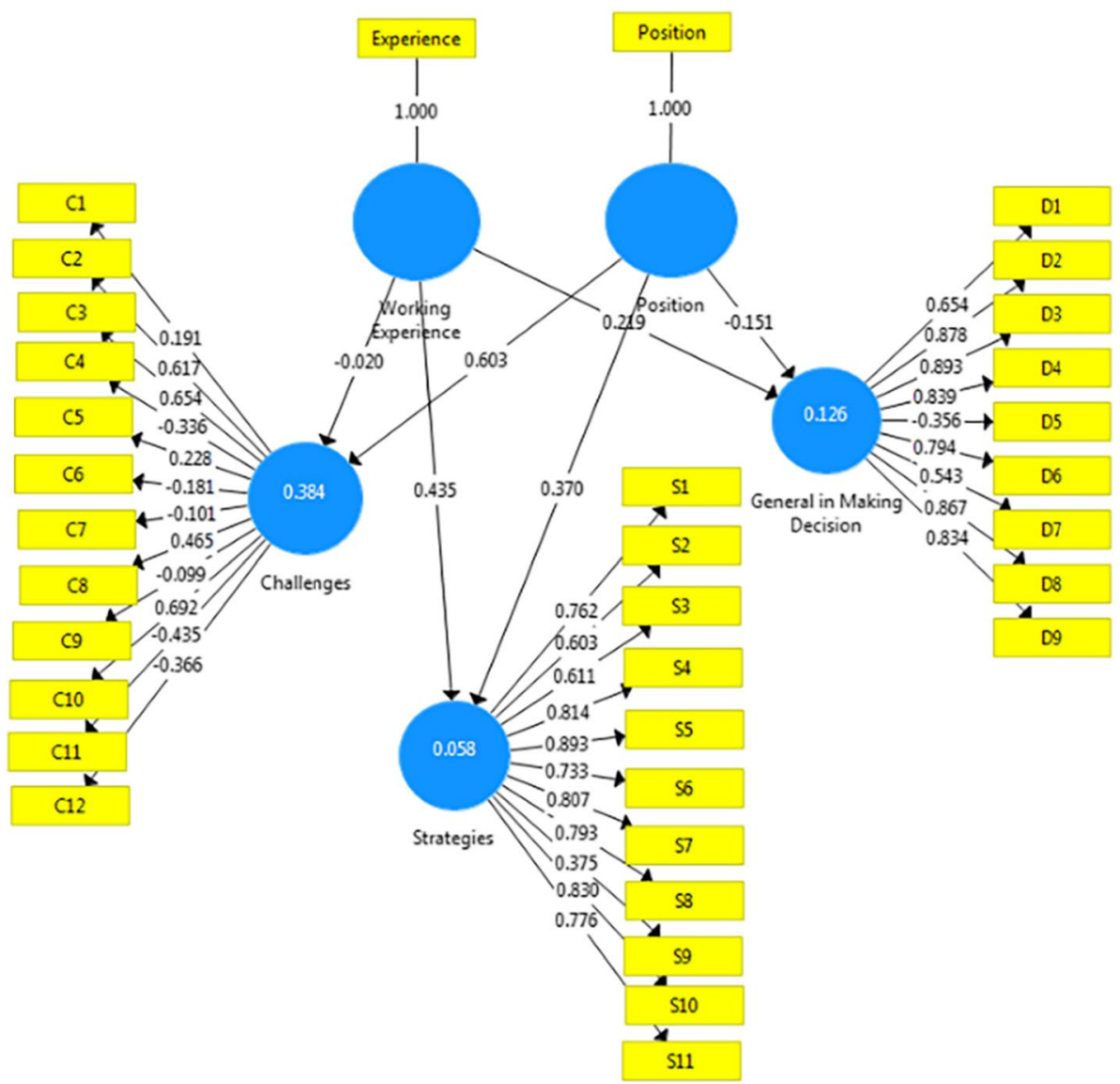

BIM-LEAN experts in organizations could be another barrier to implementing BIM-LEAN in QS practice, and this, in turn, could further affect the decision-making process to adopt BIM-LEAN thus initiating a death spiral. The strategies are divided into two main components including internal actions and external actions. Leadership and motivation from senior management of an organization take a pivotal role in internal actions while government/ 


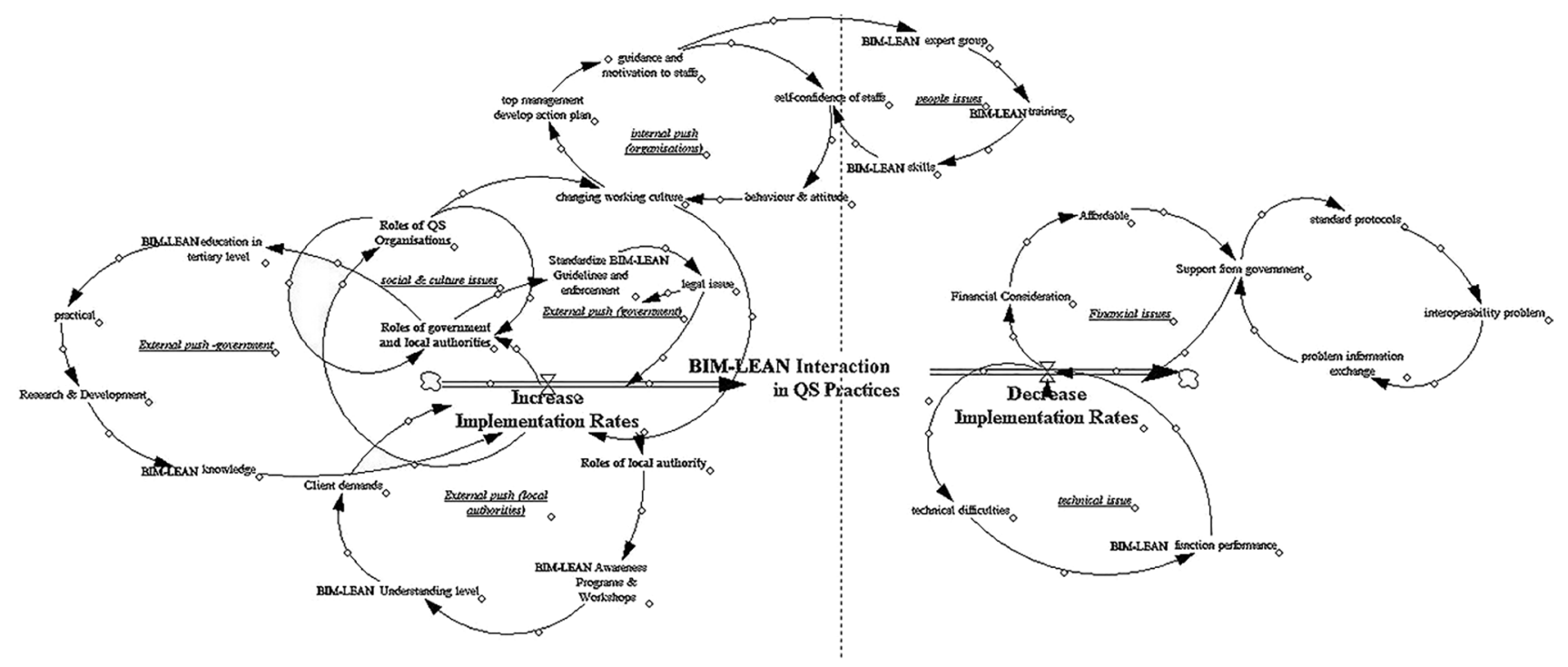

Fig. 8 System dynamics model for BIM-LEAN interaction in sustainable QS production development

local authorities in external roles. A top-down approach is recommended. It is the top management's responsibility to initiate full motivation and to provide training programs. Government and local authorities could cooperate with private sectors to organize awareness programs, conferences, workshops, and talks to initiate and enforce the use of BIMLEAN. The concern "BIM-LEAN will grab QS's job" is rejected by respondents, and therefore, it is not considered in the system dynamics model. This conceptualized model is useful to engender holistic views toward the underlying dynamics of the challenges and strategies in promoting the BIM-LEAN interaction in QS practices in the Malaysian construction industry and beyond. The model unravels the associated complexity of the interrelationship among the factors through nonlinear feedback causal mapping; creating the ability to see the world as a complex system. The systemic structures of the model deliver an integrated knowledge to enhance the mental models on the interaction of the challenges and strategies to BIM-LEAN interaction. A paradigm shift in mental models of key stakeholders is vital to handle complex problems and further improve the adoption rate of BIM-LEAN in QS practices for more advanced cost modeling and management.

\section{Conclusions}

BIM-LEAN is still at its introduction stage in current quantity surveying (QS) services. The conventional functions of QSs are to conduct activities such as feasibility study, quantities take-off, cost estimation and planning as well as BQ preparation. The use of BIM-LEAN features enhances the QSs' roles and also improve the QSs' job as these conventional activities are time-consuming and prone to human errors when they are manually performed conventionally via 2D-based drawings. Therefore, the application of BIM-LEAN is highly potential to enlighten every aspect of QS Production. Thus, QSs should be fully aware of the capabilities and opportunities associated with BIM-LEAN features toward current and future QS roles. The primary challenge is financial concerns involving the cost of hardware, software, training, and other accompanying expenses. Lack of BIM-LEAN technical experts and poor top management support in practicing QS organizations further hamper the decision to invest in BIM-LEAN technology.

BIM-LEAN triggered new functions of QS such as conducting life cycle costing, value and quality management, project management, facilities management, risk analysis, and solving contractual disputes. BIM-LEAN could further enhance QS roles in automated measurement and quantification, environmental and sustainability analysis, facilities management, quality management and legal services. The strategies are divided into two main components including internal actions and external actions. Leadership and motivation from senior management of an organization take a significant role in internal actions while government/ local authorities in external roles; thus, a top-down approach is recommended to enhance BIM-LEAN interaction. It is the top management's responsibility to initiate full motivation and to provide training programs. Government and local authorities may well cooperate with private sectors to organize awareness programs, conferences, workshops, and talks to initiate and enforce the use of BIM-LEAN.

A future research avenue could play its role in the practice of QS by applying BIM-LEAN to the process on QS and cooperating with other construction parties. Because the 
success of BIM-LEAN interaction will require full collaboration among the other construction parties involved, namely clients, architects, engineers, and contractors. At the same time, a more convincing response rate on questionnaires will also increase the theoretical value of the research. Therefore, in future research, we will improve the tracking strength on questionnaire surveys and the return visit mechanism to increase the response rate on questionnaires. In addition, by improving the historical statistical data in the system dynamics model, a clearer quantitative model of mathematical functions can be established, which has stronger theoretical support for the research on the interactive application of BIM-LEAN in the practice of QS.

Acknowledgements Authors are grateful for financial support from the Fujian Provincial Department of Science and Technology through grants number 2021I0014 and 2021R0056 and 2018J05121.

Data Availability All data, models, and code generated or used during the study appear in the submitted article.

\section{References}

Abanda FH, Kamsu-Foguem B, Tah JHM (2017) BIM - New rules of measurement ontology for construction cost estimation. Eng Sci Technol Int J JESTECH 20(2):443-459. https://doi.org/10.1016/j. jestch.2017.01.007

Ahuja R, Sawhney A, Arif M (2017) Driving lean and green project outcomes using BIM: a qualitative comparative analysis. Int $\mathrm{J}$ Sustain Built Environ 6(1):69-80

Aibinu A, Venkatesh S (2014) Status of BIM adoption and the BIM experience of cost consultants in Australia. J Prof Iss Eng Educ Practice. https://doi.org/10.1061/(asce)ei.1943-5541.0000193

Al Hattab M, Hamzeh F (2015) Using social network theory and simulation to compare traditional versus BIM-lean practice for design error management. Autom Constr 52:59-69. https://doi.org/10. 1016/j.autcon.2015.02.014

Almarshad AK (2012) BIM-based knowledge management for building maintenance. Springer, Berlin

Alshamrani OS (2017) Construction cost prediction model for conventional and sustainable college buildings in North America. J Taibah Univ Sci 11(2):315-323. https://doi.org/10.1016/j.jtusci. 2016.01.004

Alufohai AJ (2012) MRICS, \& FNIQS. Adoption of building information modeling and Nigeria's quest for project cost management

Arayici Y, Coates P, Koskela L, Kagioglou M, Usher C, O'Reilly K (2011) Technology adoption in the BIM implementation for lean architectural practice. Autom Constr 20(2):189-195. https://doi. org/10.1016/j.autcon.2010.09.016

Ashworth A, Hogg K, Higgs C (2013) Willis's practice and procedure for the quantity surveyor. Wiley, New York

Babalola O, Ibem EO, Ezema IC (2019) Lean construction: an approach to achieving sustainable built environment in Nigeria. Paper presented at the $3 \mathrm{rd}$ international conference on science and sustainable development (ICSSD), Covenant Univ Ctr Res \& Innovat Dev, Ota, NIGERIA

Babatunde SO, Ekundayo D, Babalola O, Jimoh JA (2018) Analysis of the drivers and benefits of BIM incorporation into quantity surveying profession: academia and students' perspectives.
J Eng Des Technol 16(5):750-766. https://doi.org/10.1108/ jedt-04-2018-0058

Babatunde SO, Perera S, Ekundayo D, Adeleye TE (2019) An investigation into BIM-based detailed cost estimating and drivers to the adoption of BIM in quantity surveying practices. J Financ Manag Prop Constr 25(1):61-81. https://doi.org/10.1108/ jfmpc-05-2019-0042

Dainty A, Leiringer R, Fernie S, Harty C (2017) BIM and the small construction firm: a critical perspective. Build Res Inf 45(6):696-709. https://doi.org/10.1080/09613218.2017.12939 40

Dallasega P, Revolti A, Sauer PC, Schulze F, Rauch E (2020) BIM, augmented and virtual reality empowering lean construction management: a project simulation game. Procedia Manuf 45:49-54. https://doi.org/10.1016/j.promfg.2020.04.059

Darko A, Chan APC, Yang Y, Tetteh MO (2020) Building information modeling (BIM)-based modular integrated construction risk management-critical survey and future needs. Comput Ind. https:// doi.org/10.1016/j.compind.2020.103327

Dave B, Kubler S, Framling K, Koskela L (2016) Opportunities for enhanced lean construction management using Internet of Things standards. Autom Constr 61:86-97. https://doi.org/10.1016/j.autcon.2015.10.009

Dave B, Kubler S, Pikas E, Holmström J, SinghV, Främling K et al (2015) Intelligent products: shifting the production control logic in construction (with lean and BIM)

Ding LY, Zhou Y, Luo HB, Wu XG (2012) Using nD technology to develop an integrated construction management system for city rail transit construction. Autom Constr 21:64-73. https://doi.org/ 10.1016/j.autcon.2011.05.013

Fadeyi MO (2017) The role of building information modeling (BIM) in delivering the sustainable building value. Int J Sustain Built Environ 6(2):711-722. https://doi.org/10.1016/j.ijsbe.2017.08.003

Fercoq A, Lamouri S, Carbone V (2016) Lean/Green integration focused on waste reduction techniques. J Clean Prod 137:567578. https://doi.org/10.1016/j.jclepro.2016.07.107

Garza-Reyes JA (2015) Lean and green-a systematic review of the state of the art literature. J Clean Prod 102:18-29. https://doi.org/ 10.1016/j.jclepro.2015.04.064

Gibson G, Hamilton MJA, Texas: Construction Industry Institute, The University of Texas at Austin (1994) Analysis of pre-project planning effort and success variables for capital facility projectssource document, vol 105

Greenstreet R (2003) Legal and contractual procedures for architects

Grilo A, Jardim-Goncalves R (2010) Value proposition on interoperability of BIM and collaborative working environments. Autom Constr 19(5):522-530. https://doi.org/10.1016/j.autcon.2009.11. 003

Guerra BC, Leite F, Faust KM (2020) 4D-BIM to enhance construction waste reuse and recycle planning: case studies on concrete and drywall waste streams. Waste Manag 116:79-90. https://doi.org/ 10.1016/j.wasman.2020.07.035

Heravi G, Rostami M, Kebria MF (2020) Energy consumption and carbon emissions assessment of integrated production and erection of buildings' pre-fabricated steel frames using lean techniques. J Clean Prod 253:120045. https://doi.org/10.1016/j.jclepro.2020. 120045

Heravi G, Kebria MF, Rostami M (2021) Integrating the production and the erection processes of pre-fabricated steel frames in building projects using phased lean management. Eng Constr Archit Manag 28(1):174-195

Ismail NAA, Adnan H, Bakhary NA, IOP (2019) Building information modelling (BIM) adoption by quantity surveyors: a preliminary survey from Malaysia. Paper presented at the 3rd international workshop on renewable energy and development (IWRED), Guangzhou, PEOPLES R CHINA 
Koseoglu O, Nurtan-Gunes ET (2018) Mobile BIM implementation and lean interaction on construction site: a case study of a complex airport project. Eng Constr Archit Manag 25(10):1298-1321

Lee S et al (2012) An application of lean design of structural floor system using structural building information modeling (s-bim). Adv Sci Lett 13(1):158-164

Liu HX, Lu M, Al-Hussein M (2016) Ontology-based semantic approach for construction-oriented quantity take-off from BIM models in the light-frame building industry. Adv Eng Inform 30(2):190-207. https://doi.org/10.1016/j.aei.2016.03.001

Matthews J, Love PED, Mewburn J, Stobaus C, Ramanayaka C (2018) Building information modelling in construction: insights from collaboration and change management perspectives. Prod Plan Control 29(3):202-216. https://doi.org/10.1080/09537287.2017. 1407005

Nagalingam G, Jayasena HS, Ranadewa KATO (2015) Building information modelling and future quantity surveyor's practice in sri lankan construction industry

Nascimento D, Caiado R, Tortorella G, Ivson P, Meirino M (2018) Digital Obeya Room: exploring the synergies between BIM and lean for visual construction management. Innov Infrastr Solut. https://doi.org/10.1007/s41062-017-0125-0

O'Brien WJ (2000) Implementation issues in project Web sites: a practitioner's viewpoint. J Manag Eng 16(3):34-39. https://doi.org/10. 1061/(asce)0742-597x(2000)16:3(34)

Olatunji OA, Lee JJS, Chong HY, Akanmu AA (2021) Building information modelling (BIM) penetration in quantity surveying (QS) practice. Built Environ Project Asset Manag 11(5):888-902. https://doi.org/10.1108/bepam-08-2020-0140

Olsen D, Taylor JM (2017) Quantity take-off using building information modeling (BIM), and its limiting factors. In: Hajdu M, Skibniewski ME (eds) Creative construction conference 2017, Ccc 2017, vol 196, pp 1098-1105

Oraee M, Hosseini MR, Edwards DJ, Li H, Papadonikolaki E, Cao DP (2019) Collaboration barriers in BIM-based construction networks: a conceptual model. Int J Project Manag 37(6):839-854. https://doi.org/10.1016/j.ijproman.2019.05.004

Oskouie P, Gerber D, Alves T, Becerikgerber B (2012) Extending the interaction of building information modeling and lean construction. In: Conference of the international group for lean construction

Sacks R, Koskela L, Dave BA, Owen R (2010) Interaction of lean and building information modeling in construction. J Constr Eng Manag 136(9):968-980. https://doi.org/10.1061/(asce)co.19437862.0000203
Sacks R, Barak R, Belaciano B, Gurevich U, Pikas EJLCJ (2013) KanBIM workflow management system: prototype implementation and field testing. Lean Constr J 2013:19

Said H (2016) Modeling and likelihood prediction of prefabrication feasibility for electrical construction firms. J Constr Eng Manag. https://doi.org/10.1061/(asce)co.1943-7862.0001051

Saieg P, Sotelino ED, Nascimento D, Gusmao Caiado RG (2018) Interactions of building information modeling, lean and sustainability on the architectural, engineering and construction industry: a systematic review. J Clean Prod 174:788-806. https://doi.org/10. 1016/j.jclepro.2017.11.030

Saka AB, Chan DWM (2020) Knowledge, skills and functionalities requirements for quantity surveyors in building information modelling (BIM) work environment: an international Delphi study. Archit Eng Des Manag 16(3):227-246

Sepasgozar SME et al (2021) Lean practices using building information modeling (BIM) and digital twinning for sustainable construction. Sustainability 13(1):161

Sepasgozar SME, Hui FKP, Shirowzhan S, Foroozanfar M, Yang LM, Aye L (2021) Lean practices using building information modeling (BIM) and digital twinning for sustainable construction. Sustainability 13(1):161

Swei O, Gregory J, Kirchain R (2017) Construction cost estimation: a parametric approach for better estimates of expected cost and variation. Transp Res Part B Methodol 101:295-305. https://doi. org/10.1016/j.trb.2017.04.013

Wang C, Lee YL, Yap JBH, Abdul-Rahman H (2018) Capabilitiesbased forecasting model for innovation development in smalland-medium construction firms (SMCFS). J Civ Eng Manag 24(3):167-182. https://doi.org/10.3846/jcem.2018.1626

Wao JO, Flood I (2016) The role of quantity surveyors in the international construction arena. Int J Constr Manag 16(2):126-137. https://doi.org/10.1080/15623599.2016.1142251

Yap JBH, Lock A (2017) Analysing the benefits, techniques, tools and challenges of knowledge management practices in the Malaysian construction SMEs. J Eng Des Technol 15(6):803-825. https:// doi.org/10.1108/jedt-07-2017-0067

Yap JBH, Skitmore M (2018) Investigating design changes in Malaysian building projects. Archit Eng Des Manag 14(3):218-238. https://doi.org/10.1080/17452007.2017.1384714

Ying TY, Kamal EM (2021) The revolution of quantity surveying profession in building information modelling (BIM) era: The Malaysian perspective. Int J Sustain Constr Eng Technol 12(1):185-195. https://doi.org/10.30880/ijscet.2021.12.01.019 